\title{
Factors Affecting to Tea-Growing Household's Financial Efficiency: A Case Study from Thai Nguyen Province
}

\author{
Tran Thi Quy Chinh ${ }^{1,2}$, Tran Cuong1,3*, Jiancheng Chen ${ }^{1}$ \\ ${ }^{1}$ School of Economics and Management, Beijing Forestry University, Beijing, China \\ ${ }^{2}$ SaoDo University, ChiLinh City, Socialist Republic of Vietnam \\ ${ }^{3}$ Department of Economic and Rural Development, Thai Nguyen University of Agriculture and Forestry, ThaiNguyen City, \\ Socialist Republic of Vietnam \\ Email: *trancuong2288@gmail.com
}

How to cite this paper: Chinh, T.T.Q., Cuong, T. and Chen, J.C. (2020) Factors Affecting to Tea-Growing Household's Financial Efficiency: A Case Study from Thai Nguyen Province. Open Access Library Journal, 7: e6969.

https://doi.org/10.4236/oalib.1106969

Received: November 8, 2020

Accepted: December 7, 2020

Published: December 10, 2020

Copyright $\odot 2020$ by author(s) and Open Access Library Inc.

This work is licensed under the Creative Commons Attribution International License (CC BY 4.0).

http://creativecommons.org/licenses/by/4.0/

\begin{abstract}
Due to one of the major tea-producing regions of the country, the quality and brand have been affirmed, Thai Nguyen province has identified tea as the main crop to develop local economy as well as improve farm households income. The main objective of this study is analyzing the financial efficiency of tea farmers in Thai Nguyen province through the data collected from 210 households. The results indicated that the financial efficiency of tea cultivation is quite high with the rate of return on total cost of $48.97 \%$. In addition, there are five factors related to the production stage that affect the financial efficiency of tea farmers, of which three factors that have a positive impact were productivity, credit access, training technical and two negative impact factors were tea area and risk. Thence, this study recommends solutions to enhance the financial efficiency such as improving tea yields, reducing input costs, strengthening activities of cooperatives, and maintaining techniques training as well as advancing ability access to credit for farmers.
\end{abstract}

\section{Subject Areas}

Agricultural Engineering, Environmental Economics, Financial Reporting

\section{Keywords}

Financial Efficiency, Tea Farmers, Training, Factor, Thai Nguyen

\section{Introduction}

Currently, Vietnam is one of the world's largest tea producers and exporters. In 
Vietnam, there are thirty-four provinces developed tea tree with a total area of 123 thousand hectares of tea, annual productivity about 11.5 tons/ha, yield approximately 1.02 million tons of fresh tea buds; export volume reached 136 thousand tons and the value reached 235 million USD [1]. Over the past years, due to the high economic efficiency, the tea area has been continuously expanded, the tea productivity was improved. Thereby, it was playing an important role in local economic development, and especially in poverty reduction for ethnic groups in the northern mountainous region of Vietnam.

Thai Nguyen is a province in Northeast Vietnam, with an area of $3562.82 \mathrm{~km}^{2}$, population approximately 1.364 million [2]. Due to an important geographical location province, Thai Nguyen also is a major economic, political and educational center of the northern midland and mountainous region. It is characterized by the topography of mountains with the temperature, water quantity, and light conditions being suitable for tea production. Currently, Thai Nguyen province considered as a famous tea region of Vietnam with tea is grown in all administrator units of province with a total tea-producing area of approximately 22,300 hectares and more than 70,143 households involved in tea production, it is considered the second largest tea area in the country. Tea trees have played an important role in the agricultural sector of province when the production value of tea contributes about $20 \%$ of the total production value of the province's crop. By the end of 2019, the average yield is $14,000 \mathrm{~kg} / \mathrm{ha}$ [3]. In recent years, Thai Nguyen has promoted the transformation of tea variety structure, application of science and technology in tea production as well as trade promotion, and enhances abilities of tea consumption. Although there are previous studies on the tea value chain in Vietnam and research to develop tea growing procedures according to VietGap ${ }^{1}$ standards in Thai Nguyen province [4] [5], there are no studies to analyze the financial efficiency of tea growers. Therefore, this study will analyze the financial efficiency as well as factors affecting the financial efficiency of tea growers, thereby it will propose solutions to improve financial efficiency for local farmers in study area.

\section{Research Method}

\subsection{Research Data}

Thai Nguyen is a province of the Northern Midlands and Mountains of Vietnam, distance about $45 \mathrm{~km}$ South of Hanoi Capital (Figure 1). Thai Nguyen's topography is characterized by many high mountain ranges running from north to south. The structure of the northern mountains is mainly strongly weathered, forming many caves and small valleys. Thai Nguyen province has a population of about 1364 million people with 8 ethnic groups living together including: Kinh, Tay, Nung, San Diu, San Chay, Dao, H'Mong and Hoa with a population density of about 327 people per $\mathrm{km}^{2}$. The province has a total area about 3562.82 $\mathrm{km}^{2}$ divided into 2 cities, 1 town and 6 districts. These administrative units are ${ }^{1}$ Regulations on high quality agricultural production practices for agricultural and fishery products in Vietnam. 


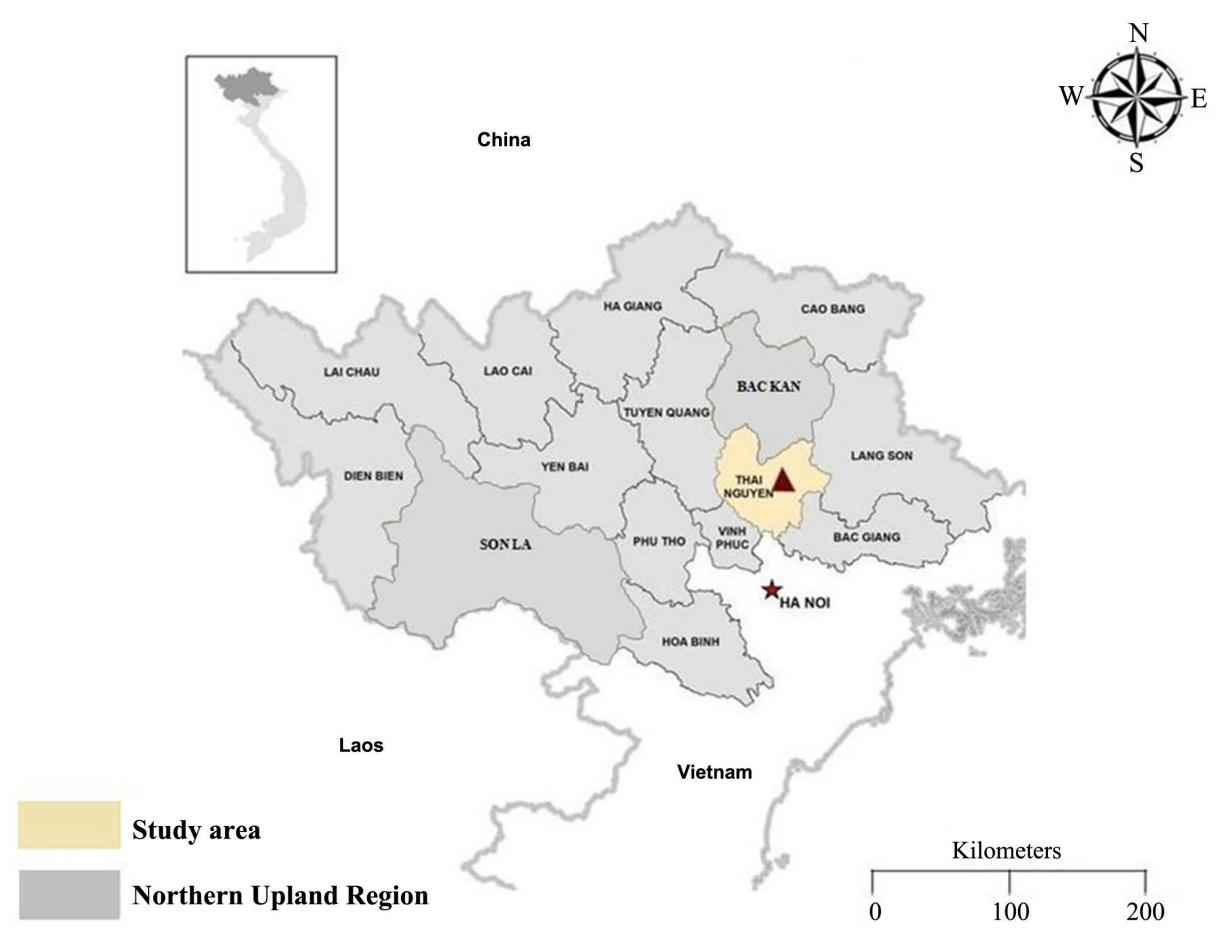

Figure 1. Map of study area. Source: Department of Natural Resources and Environment of Thai Nguyen.

further subdivided into 180 commune-level administrative units (including 32 wards, 9 towns, and 139 communes), including 125 highland and mountainous communes, the rest are delta communes and midland [2].

Household's data were used to analyze the factors, which influence household financial efficiency. The data were collected from a sample survey, which includes 210 tea-producing households in the Thai Nguyen province. As shown in Table 1, we selected three district with the largest number of tea growing households include Thai Nguyen, Dai Tu and Dong Hy, of which, there are three districts with the largest tea area in Thai Nguyen province (accounting for 85\% of the tea growing area of the whole province) and has a long tradition of growing tea. For each district, we selected the commune with the largest number of tea growing households including Tan Cuong, Phuc Xuan, Phuc Triu of Thai Nguyen city; La Bang, Yen Lang of Dai Tu district; Trai Cai, Van Han of Dong Hy province.

Secondary data was collected from documents related to farm household production, application of science and technology in agricultural production, including reports, research, Statistical Yearbook in Thai Nguyen province.

\subsection{Analysis Methods}

This study used descriptive statistical methods with criteria such as mean, maximum value, minimum value, and frequency. The financial efficiency of tea growers is measured by the ratio of profit/total cost (\%) [6]. Total cost (TC) is all the investment costs that the farmer used in the production and harvesting process 
Table 1. Surveyed households in the study area.

\begin{tabular}{cccc}
\hline District & Commune & Village & No. of surveyed households \\
\hline \multirow{3}{*}{ Thai Nguyen city } & Tan Cuong & Hong Thai 1 & 30 \\
& Phuc Xuan & Trung Tam & 30 \\
& Phuc Triu & Lai Thanh & 30 \\
\hline Dai Tu district & La Bang & La Bang & 30 \\
& Yen Lang & Đong Đinh & 30 \\
\hline Dong Hy district & Trai Cai & Trai Cai 1 & 30 \\
& Van Han & Van Han 1 & 30 \\
\hline Total & & & 210 \\
\hline
\end{tabular}

Source: Survey data 2019.

includes seed costs, fertilizers, chemical medicines, labor, transportation, fuel, energy and harvest etc.

Total cost $=$ Labor cost + Material cost + other expenses.

Revenue (TR): This is the total amount earned from the household's consumption of products, service provision, financial activities and other activities.

$$
\text { Revenue }=\text { Selling price }{ }^{*} \text { Total output }
$$

Profit $(\Pi)$ : is the remainder of the total value of the product minus the total cost.

$$
\text { Profit }=\text { Gross product value }- \text { total cost }
$$

Productivity is the average quantity produced per unit of input and it is used to standard measure the efficiency of production's input use factors. Productivity by input factors such as labor and capital.

$$
\text { Productivity }=\text { Output/Unit area }
$$

Profit per Cost (PPC): the index measures the efficiency of the investment, reflecting a dong of investment costs, how much profit will the investor earn.

$$
\text { PPC }=\text { Profit } / \text { Total Cost }
$$

Profit/revenue (ROS): The index reflects the margin of profit; it reflects the level of profit compared to the total revenue, in revenue how many VND of profit.

Multiple regression analysis of factors affecting the return on total cost of tea growers. In this article, the author chooses the following factors to analyze the impact of these factors on the financial efficiency of tea farmers. The OLS specification model for financial efficiency is:

$$
\begin{aligned}
Y= & \beta_{0}+\beta_{1} \cdot X_{1}+\beta_{2} \cdot X_{2}+\beta_{3} \cdot X_{3}+\beta_{4} \cdot X_{4}+\beta_{5} \cdot X_{5} \\
& +\beta_{6} \cdot X_{6}+\beta_{7} \cdot X_{7}+\beta_{8} \cdot X_{8}+\beta_{9} \cdot X_{9}+\varepsilon
\end{aligned}
$$

Symbolic names of variables and definitions are presented in Table 2.

Where $Y_{i}$ denotes the household's financial efficiency, $X_{i}$ is a vector of explanatory variables influencing financial efficiency, $\beta_{0}$ is the constant and $\beta_{i}$ is the 
Table 2. Explanatory variables.

\begin{tabular}{|c|c|c|}
\hline Variable name & Symbol & Variables Description \\
\hline Financial efficiency & $Y$ & $\begin{array}{l}\text { The financial performance of tea growers is measured by the } \\
\text { ratio of profit/total cost (\%). }\end{array}$ \\
\hline Academic level & $X_{1}$ & Get the equivalent of the class number of the main employee \\
\hline Experience & $X_{2}$ & $\begin{array}{l}\text { Years of experience of the main labor of households engaged in } \\
\text { tea cultivation }\end{array}$ \\
\hline Join a cooperative & $X_{3}$ & $\begin{array}{l}\text { Assumes } 1 \text { if the household participates in the cooperative and } 0 \\
\text { otherwise }\end{array}$ \\
\hline Technical training & $X_{4}$ & $\begin{array}{l}\text { Assumes } 1 \text { if the household participates in tea cultivation } \\
\text { techniques and } 0 \text { otherwise }\end{array}$ \\
\hline $\begin{array}{l}\text { According to quality } \\
\text { standards }\end{array}$ & $X_{5}$ & $\begin{array}{l}\text { Receive } 1 \text { if the household grows tea according to VietGap } \\
\text { standards and } 0 \text { otherwise }\end{array}$ \\
\hline Credit access & $X_{6}$ & $\begin{array}{l}\text { Receives value of } 1 \text { if the household has access to a loan for tea } \\
\text { cultivation and zero value otherwise }\end{array}$ \\
\hline Production area & $X_{7}$ & Area of tea cultivation in the production season is surveyed ( ha) \\
\hline Productivity & $X_{8}$ & Tea yield achieved in the survey season $(\mathrm{kg} / 1 \mathrm{ha})$ \\
\hline Risk & $X_{9}$ & $\begin{array}{l}\text { Receives value of } 1 \text { if the household has risk and zero with value } \\
\text { otherwise }\end{array}$ \\
\hline
\end{tabular}

Source: Results from literature review and preliminary research, 2019.

vector of coefficients which will be estimated and $\mathrm{Ui}$ is the unobservable random disturbance or error term. F-statistic was also used at $95 \%$ confidence level to test the relationship between financial efficiency and factors affecting it; Variance Inflation Factor (VIF) was used to test Multicollinearity phenomenon; numeric value Durbin-Watson statistical was used to test Autocorrelation phenomenon. The problem of heteroscedasticity also was examined in our data using White's general heteroscedasticity Test. The STATA software used to calculate and to diagnostic tests at significance levels of 95 percent.

\section{Results and Discussion}

\subsection{Current Situation of Tea Production by Farmers}

The study surveyed 210 tea farmers in 2019 in Thai Nguyen province, these farmers have grown tea more than 4 years. As shown in Table 3, the average age of the surveyed farmers is 40.69 years old (from 19 to 76 years old); Of which many older farmers are involved in tea growing activities. The education level of tea growers is quite hight, $41 \%$ of them are from grade 10 or above, so farmers will have many advantages in accessing and applying science and technology to production. Farmers surveyed have an average of 17 years of tea growing experience (from 4 to 48 years). The experience of production helps farmers to cope well with diseases on tea, take good care of plants and this directly affects tea productivity and farm profits.

Join cooperatives: Through the field survey, there are $88.1 \%$ of farmers join tea-growing cooperatives (Figure 2). Cooperative activities mainly share information with each other in the buying and selling stages and have not yet done 
Table 3. Characteristics of tea farmers.

\begin{tabular}{ccccc}
\hline Indicator & Unit & Max & Min & Average \\
\hline Age of main employee & Year & 73 & 19 & 40.69 \\
Education level of main employees & Year & 12 & 0 & 7.97 \\
Experience & Year & 48 & 4 & 17.08 \\
Tea area & ha & 2.8 & 0.5 & 1.48 \\
Productivity & Kg/ha & 17,000 & 12,680 & 15,382 \\
\hline
\end{tabular}

Source: Survey data 2019.

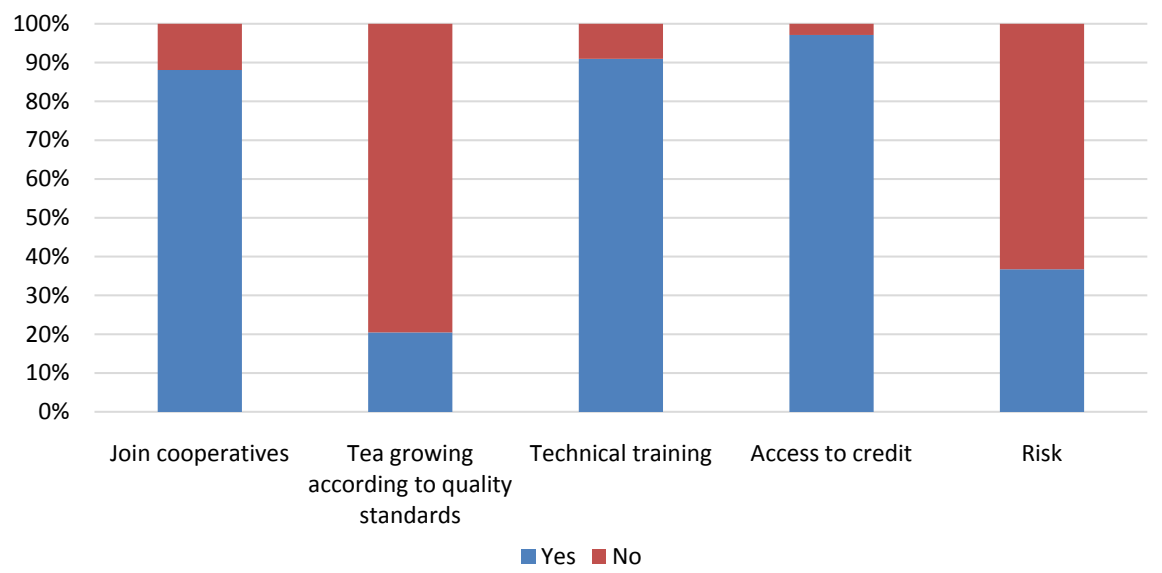

Figure 2. Characteristic of farmer's tea cultivation. Source: Survey data 2019.

the linkage in production, purchasing input materials and not yet linked to tea consumption.

Tea growing according to quality standards: Survey results shown that $20.48 \%$ of farmers grow tea according to VietGap standards (Figure 2). In fact, growing tea according to VietGap standards helps farmers to produce quality products as well as to ensure the health of them involved in production, to have the opportunity to consume high prices.

Technical training: These technical training courses will help farmers access to planting techniques, prevention and treatment of tea pests will contribute to improving productivity and profitability for farmers. Tea is a crop that is considered to bring high economic efficiency and localities with tea-intensive regions interested in transferring production technology process to farmers through technical training and implementation of tea growing models [7]. The survey results show that $90.95 \%$ have been trained in tea cultivation techniques (Figure 2).

Access to credit: $97.14 \%$ of responder from field survey answered that they had access to loans from banks or private individuals to grow tea, this results indicated that access to credit plays an important role on tea production activities (Figure 2). In addition, tea growers are also provided with credit through the purchase of seeds and agricultural materials from agents.

Risk: Farmers' agricultural production is exposed to many risks [8], of which 
weather and natural disasters are the most common. The results shown that more than $37.14 \%$ of tea farmers faced on risk during the previous production season. Less rain and drought lasted also lead to decrease in tea productivity. There is also a risk of market, when Vietnamese tea products were increasingly competed with others' products in the world.

\subsection{Financial Efficiency of Tea Farmers}

The total cost of tea cultivation includes the following costs: Manure, fertilizer, pesticides, labor, machines, electricity, water. Tea is a very labour-intensive product to grow: labour costs account for around half the costs of production. Tea prices in the market fluctuate strongly at different times of the year. The price of fresh tea buds in 2018 was on average $9000 \mathrm{VND} / \mathrm{kg}$ and an average yield of 15.382 tons/ha, the revenue is 14.0145 million VND/ha. This profit margin is higher than that of the paddy cultivation model at the same time in Thai Nguyen province [5]. Furthermore, the farmer's ratio of return to total tea planting costs is quite high, averaging $48.97 \%$ during the year average production season (Table 4). Compared with the capital market interest rate or the profitability rate of other paddy and vegetable cultivation models in the study area, the financial efficiency of tea farmers is higher. On the other hand, the results also indicated that there are not the tea growers suffered losses during the survey year, and a few households had low financial efficiency at just over $20 \%$.

\subsection{Factors Affecting Financial Efficiency of Tea Farmers}

To test the hypothesis that the factors affect the financial efficiency of tea farmers in Thai Nguyen province, multiple regression models have been developed, the values estimated of the regression coefficients were tested for statistical significance. The results of multiple regression models are represented in Table 5. $\mathrm{R}^{2}$ value of 0.5205 indicated that $52.05 \%$ the variation of household's is caused by the effect of these independent variables and $23.62 \%$ is caused by other factors. On the other hand, the significant of F-test $<0.01$ mean the regression model always exists with a confidence level of $99 \%$; the variance inflation factors coefficient (VIF) is less than 10, so the regression model has not multicollinearity phenomenon; At the same time, the test results of Heteroskedasticity (IM-test) show that the phenomenon of variance in the models is not significant.

Table 4. Financial efficiency in tea production by farmers.

\begin{tabular}{ccccc}
\hline Indicator & Unit & Max & Min & Average \\
\hline Total cost & 1000VND/ha & 112,828 & 78,797 & 94,363 \\
Revenue & $1000 \mathrm{VND} / \mathrm{ha}$ & 162,850 & 121,500 & 140,145 \\
Profit & $1000 \mathrm{VND} / \mathrm{ha}$ & 68,703 & 22,419 & 45,781 \\
Profit/total cost (PPC) & $\%$ & 87.52 & 21.56 & 48.97 \\
Profit/Revenue (ROS) & $\%$ & 46.67 & 17.76 & 32.54 \\
\hline
\end{tabular}

Source: Survey data 2019. 
Table 5. Factors affecting financial efficiency of tea growers.

\begin{tabular}{cccc}
\hline Variables $^{\mathrm{P}}>\mathbf{| t |}$ & Coefficients & VIF \\
\hline Education $^{\mathrm{NS}}$ & 0.121 & -0.000835 & 4 \\
Experience $^{\mathrm{NS}}$ & 0.258 & -0.000598 & 3.97 \\
Tea area $^{* *}$ & 0.000 & -0.128150 & 1.91 \\
Training $^{* *}$ & 0.013 & 0.019650 & 1.61 \\
Association $^{\mathrm{NS}}$ & 0.460 & -0.039383 & 1.56 \\
Risk $^{* *}$ & 0.000 & -0.091434 & 1.37 \\
Credit access $^{* *}$ & 0.015 & 0.015980 & 1.35 \\
Productivity $^{* * *}$ & 0.006 & 0.000008 & 1.15 \\
VietGap standards $^{\mathrm{NS}}$ & 0.255 & -0.012468 & 1.14 \\
_cons & 0.955 & -0.340339 & - \\
Sig.F & & 0.0000 & \\
R-squared & & 0.5205 & \\
IM-test & & 0.5199 & \\
\hline
\end{tabular}

Source: Linear regression analysis results from survey data, $2019 .{ }^{\star} \mathrm{P}<0.1 ;{ }^{*} \mathrm{P}<0.05 ;{ }^{\star * *} \mathrm{P}<0.01$; ${ }^{\mathrm{NS}}$ No significant statistical.

The multivariate regression model is used to determine the factors that affect the financial efficiency of tea growers, where the rate of return to total cost that reflects the profitability of total costs is the secondary variable belongs to $(Y)$ and 9 independent variables.

Table 4 describes the findings on socio-economic factors influencing household financial efficiency in study area. The findings revealed that education, experience and participant to association have no statistical significant effect on financial efficiency generated of farm households. In contrast, these variables such as technical training, credit and productivity were found to have a positive effect on the household's financial efficiency in the study area. There are $90.95 \%$ of farmers receiving technical training and the analysis shows that the training is really beneficial and contributes to improving the financial efficiency of tea farmers. This similar to observed by Mishr [9] and Akhilomen [10]. Recognizing the importance of technical training to tea production efficiency, tea farmers in Thai Nguyen province always actively participate in technical training courses. The training class spent most of the time for trainees to practice nursery techniques, pots, and cover materials; the method of using A-ruler to design newly planted tea fields and cross green trees along contour lines to prevent erosion on sloping land; techniques of intercropping, planting shade trees in tea gardens; dig holes, fertilize before planting; select standard seedlings; balanced fertilization technique for each period of growth and development; organic composting technique with microbiological products; canopy pruning techniques; how to prepare herbal medicine spray insecticides for tea plants; how to recognize, harvest and preserve high-quality tea. The results from the regression 
model showed that the households applying modern irrigation technology could have financial efficiency higher about $1.965 \%$ than other household groups with a $5 \%$ significance level. For tea growers, credit is extremely important [11]. Most tea growers in Thai Nguyen have access to preferential credit such as low interest rates, long loan terms ... When they have capital, farmers will promptly equip agricultural materials for production avoid buying materials at much higher prices from material dealers. The results from the regression model show that households that have access to credit could have financial efficiency higher about $1.598 \%$ than other household groups with a $5 \%$ significance level. This finding agrees with result from Jacod [12] and Riatania Lubis [13]. Increased productivity contributes to increasing the rate of return on total costs. Productivity increased by 1 ton/1ha contributed to the increase of the profitability to total cost of farmers by nearly $8.93 \%$ (significant level $1 \%$ ). Provinces that have traditionally grown tea have always achieved a very high yield, Thai Nguyen is the province with the highest tea productivity in Vietnam.

Two factors that negatively affect the household's financial performance are tea acreage and risks. This shows that the larger the tea acreage, the lower the financial efficiency of the farmer. This problem can be explained as follows: Among the households in the study subjects there are many households with new tea growing areas, for tea, the first stage is the most expensive period for pruning care, so it will reduce financial efficiency. In addition, the increase in tea plantation area will make it difficult for farmers in the management and calculation of reasonable costs for suitable tea acreage. With the significance level of $1 \%$, when the tea area increases to 1 ha, it reduces the financial efficiency $12.81 \%$. This results opposite with finding of Wudineh Getahun Tiruneh [14]. Each supply chain can have many different risks in the same or between stages [15]. Regarding farmers' production, there are two major types of risks: 1) risks related to weather (rainfall, temperature), natural disasters (floods, droughts) and 2) market risks fields of inputs and outputs. The risks related to weather and natural disasters will directly affect the productivity of crops and animals and thereby affect production efficiency. Market risks such as high input prices, low quality of inputs or unstable selling prices of output products will affect farmers' income and financial performance. Risks from weather disasters and risks due to the output price of the product will reduce the financial efficiency of tea growers. Significance level of $1 \%$ shows that if farmers face the above risks, financial efficiency will decrease $9.14 \%$. When the tea tree is affected by bad weather, the quality and yield of the tea are not high, this makes the tea revenue decrease, which in turn leads to the profit per total cost. In addition, like some other agricultural products, although farmers produce according to typical quality standards, ViepGap standards with production costs higher than production costs under traditional processes, but not linked. Therefore, the selling price of tea is equal to the selling price of tea grown according to the traditional process. This limitation makes the cultivation of tea according to quality standards ineffective for farmers. Therefore, farmers are not encouraged to grow tea according to 
quality standards.

\subsection{Solutions to Improve the Financial Efficiency of Tea Farmers}

To improve financial efficiency for tea growers, local authorities and farmers need to pay attention to implementing the following solutions:

Firstly, improve tea yield and reduce input costs: Relevant agencies and agencies need to manage the quality of seedlings sold in the market, and select quality seedlings with good growth for productivity high. This will help farmers reduce input costs such as costs of seeds, fertilizers, and chemicals. In addition, farmers need to reduce the amount of inorganic fertilizers, increase the use of organic fertilizers to improve the soil environment, reduce costs, and safety for users and growers.

Secondly, policy maker needs to strengthening activities of cooperatives and tea associations: Besides mobilizing farmers to join tea cooperatives or tea associations, local authorities need to take measures to help farmers in cooperation. communes link production-consumption like linking with input suppliers to buy inputs at cheaper prices, linking with purchasing units to sign consumption contracts to help farmers have stable output. quantity and price. To do this, it is necessary to improve the management capacity and market capacity for the leaders of cooperatives and associations.

Thirdly, local authorities continue maintaining tea cultivation techniques training for farmers, especially new knowledge about prevention and treatment of pests and diseases in tea, how to use organic fertilizers and the necessary amount of irrigation water for tea plants. Besides, it is necessary to guide farmers on measures to cope with climate change.

Fourthly, creating easy conditions for farmers to access credit capital. There should be policies to encourage farmers to grow tea by lending farmers loans with many incentives such as low interest rates, no mortgage, long loan periods etc.

\section{Conclusion}

Through analysis of data collected from 210 tea farmers from Thai Nguyen province, the study has shown that the profitability of tea farmers' model was high, averaging about 45 million VND/ha and the financial efficiency of tea farmers was found quite high. In addition, the rate of return on revenue was approximately $32.54 \%$ and the rate of profit per total cost was approximately $48.97 \%$, the results lead many localities considering tea trees to be a crop of high economic efficiency. However, tea farmers also face many risks due to weather, pests and diseases, selling price, etc. The analysis results of nine factors in the production and consumption of tea farmers to determine the factors affecting the financial efficiency of tea cultivation have shown that there are three factors: tea yield, participation in credit, technical training have positive impacts and two factors of tea planting area and the risk have negative impacts on the financial 
performance of tea farmers. Meanwhile, the factors as household characteristic (education, experience), tea production according to VietGap standards have no statistically significant on the financial performance of tea growers. Thus, in order to improve profits as well as increase financial efficiency for tea growers, some solutions have been indicated such as 1) improving tea productivity and reducing input costs; 2) strengthening activities of tea cooperatives and associations; 3) maintaining tea planting techniques training for farmers; 4) improving rural credit access capacity.

\section{Conflicts of Interest}

The authors declare no conflicts of interest regarding the publication of this paper.

\section{References}

[1] Vietnam, G.S.O. (2019) Statistics on the Development of a Number of Perennial Crops.

[2] Department of Natural Resources and Environment of Thai Nguyen (DNRE) (2019) General Report.

[3] Department of Statistics of Thai Nguyen Province (2019) Report on the Socio-Economic Development of Thai Nguyen Province in 2019.

[4] Mai, N.T.T. (2020) Study Some Measures to Improve Tea Production Efficiency According to Vietgap Standards in Lam Dong. Vietnam Academy of Agricultural Sciences, Hà Nội.

[5] Chung, H.V. (2012) Build a Safe Tea Production Model According to VIETGAP Standards. Thai Nguyen Agriculture and Forestry University, Thái Nguyên.

[6] La Nguyễn Thùy Dung, M.V.N. (2015) Analyze the Financial Efficiency of Rice Producing Households According to the Model Linked with Enterprises in an Giang Province. Scientific Journal of Can Tho University, 36, 92-100.

[7] Gatimbu Karambu, K. and Ogada Maurice, J. (2020) Technical Efficiency of the Small-Scale Tea Processors in Kenya: A Stochastic Metafrontier Approach. African Journal of Economic and Management Studies.

[8] Kumar, et al. (2011) Value Chains of Agricultural Commodities and Their Role in Food Security and Poverty Alleviation: A Synthesis. Agricultural Economics Research Review, 24, 169-181.

[9] Mishra, A., Wilson, C. and Williams, R. (2009) Factors Affecting Financial Performance of New and Beginning Farmers. Agricultural Finance Review, 69, 160-179. https://doi.org/10.1108/00021460910978661

[10] Akhilomen, L., et al. (2015) Economic Efficiency Analysis of Pineapple Production in Edo State, Nigeria: A Stochastic Frontier Production Approach. American Journal of Experimental Agriculture, 5, 267-280. https://doi.org/10.9734/AJEA/2015/13488

[11] Barry, P.J., Ellinger, P.N., Hopkin, J.A. and Baker, C.B. (1994) Financial Structure of Farm Businesses under Imperfect Capital Markets. American Journal of Agricultural Economics, 54, 108-190.

[12] Jacob Asravor, E.E.O. and Yaw, B. (2016) Efficiency of Chili Pepper Production in the Volta Region of Ghana. Journal of Agricultural Extension and Rural Develop- 
ment, 8, 99-110. https://doi.org/10.5897/JAERD2016.0765

[13] Lubis, R.R.B., Daryanto, A. and Tambunan, M. (2015) Analysis of the Technical Efficiency of Pineapple Production in Subang District, West Java Province, Indonesia. Journal of ISSAAS (International Society for Southeast Asian Agricultural Sciences), 21, 48-55.

[14] Wudineh, G.T. and Endrias, G. (2016) Technical Efficiency of Smallholder Wheat Farmers: The Case of Welmera District, Central Oromia, Ethiopia. Journal of Development and Agricultural Economics, 8, 39-51.

https://doi.org/10.5897/JDAE2015.0660

[15] Steven Jaffee, P.S. and Andrews, C. (2010) Rapid Agricultural Supply Chain Risk Management: A Conceptual Framework. Agriculture and Rural Development Discussion, The World Bank, Washington, 55.

http://www.agroinsurance.com/files/documents/RapApRisk.pdf 